\title{
Small Size Nanosilver Multi Organ Toxicity: A Higher Dose Negative Response in In-Vivo and In-Vitro Experimental Application
}

\author{
Jyoti Prakash Pani* and Royana Singh \\ Department of Anatomy, Banaras Hindu University, India
}

Received: September 02, 2017; Published: September 15, 2017

*Corresponding author: Jyoti Prakash Pani, Research Scholar, Department of Anatomy, Institute of Medical Sciences, Banaras Hindu University, Varanasi, Uttar Pradesh, India, Tel: 08433668356; Email: jyotiprakash.pani35@gmail.com

\begin{abstract}
Multi organ toxicity of nanosilver depends on shape and injected dose of the particle concerned. But rate of toxicity is based on mode of tissue permeability predominant in repeated oral route application. Spiny and tiny nanosilver of small size colloid cool watery solution is being extensively and serially utilized in critical but human beneficiary scientific experiment. In this existing study, we evaluated the multi organ toxic effects of various small sizes silver nanoparticles of 2.45 to 19.53 nanometer size range in pregnant Swiss Albino mouse freshly dissected internal vital abdominal viscera tissues, with different doses such as $0.37,0.65,13$ and $21 \mathrm{mg} / \mathrm{kg}$ body weight on kidney, liver and spleen tissues via oral gavages for 27 days followed by in-vivo and in-vitro application. Destructive responses on above mentioned multi abdominal viscera's were observed in high 13 and $21 \mathrm{mg} / \mathrm{kg}$ dose small size AgNps treated group, when visualized by routine histology mode. Histological and gross examination showed tissue destruction, blood tinged focuses, cell necrosis and programmed cell death dilemma from all mouse in high dose group compared to control group. But lower dose group executed negotiable effect almost equal to control. Depend on these types of hazardous features, it is postulated that the effect of small size nanosilver particles on the exposed tissues may cause multi organ vital viscera's toxicity in mice.
\end{abstract}

Keywords: Small Nanosilver, Vital Retro Peritoneal Organ, Viscera Toxicity, Primate Vertebrate of Lower Group.

\section{Introduction}

Small size nanoparticle of silver metal penetrates well in tissue micro porous. Nanosilver proves to be maximum toxic and disambiguative in small dimension but teratogenic in bigger size and larger dose, over toxic in small size (less than 20nm) than other sizes. In addition to it, nanosilver produces various type toxogenic responses due to various architectural arrangement and dimensions [1]. Nanosilver various system and body impacts along with in-vivo \& in-vitro application and multi abdominal viscera's toxicity in oral application experiment is showing worldwide recognition and acceptability. Small size Ag nano is absorbed easily directly via water in colloidal form, via food in silver foil form, via cosmetics in earrings and bangles form, via drugs in silver sulphadiazine ointment form, via drug delivery devices in nano drug delivery system with delivering needle and tuner form etc [2]. While passing through gastrointestinal tract in colloidal and liquid form it produces various types of toxicities which correspond to various horny and spiny small shapes and dimensions [3].

There are limited researches about small size nanosilver multi organ toxicity through oral application. Most of the surgical and medical instruments and devices eliminates Ag+ ion whiale performing in-vivo \& in-vitro applications which ultimately produces multi visceral organ toxicity, this thing is evidenced by famous medical and surgical nano journals [4]. Various small size range silver nano particles produces various types of toxicities in multi visceral organs [5]. This small size nano metal is utilizes for various consumer products so recent intelligent world population should alert about its multi organ toxicity in higher dose [6]. In this existing study, four different small size silver nanoparticles colloidal doses were prepared, and repeated-dose multi organ toxicity was evaluated after oral administration in pregnant Swiss Albino mice.

\section{Materials and Methods}

The sodium borohydride synthesized silver nanoparticles 2.45 to 19.53 size nanometer range, were prepared by Department of Anatomy Institute of Medical Sciences Banaras Hindu University Varanasi Uttarpradesh and characterized by IIT BHU pharmaceutical division and was suspended with 1.5 molar $\mathrm{NaCl} 2$. The size distribution was analyzed by transmission electron microscope and Delsa ${ }^{\mathrm{TM}}$ Nano Beckmann Coulter machine. The 
average size of AgNps prepared by magnetic stirring and cooling method was 11.57 nano meter (Figure 1). 50 pregnant female adult Swiss Albino mice from various colonies (age 8 to 12 weeks, weight 25 to $35 \mathrm{~g}$ ) were used in this research there were utilized from Animal house Department of Anatomy IMS, BHU. The mice were divided to five groups (10 mice per group) with each group named as 1 (Sham control group), 2 ( $0.37 \mathrm{mg} / \mathrm{kg}$ between group), $3(0.65 \mathrm{mg} / \mathrm{kg}$ between group), $4(13 \mathrm{mg} / \mathrm{kg}$ between group) and $5(21 \mathrm{mg} / \mathrm{kg}$ between group). Group 1, was called Sham control group and was given anionic double distilled water and the other four groups, 2 to 5 were called experimental groups were given small size colloidal AgNps stirring solution. All groups were kept on controlled conditions of $20 \pm 4^{\circ} \mathrm{C}$ temperature, $55 \% \pm 5$ humidity, $12 \mathrm{~h}$ light and darkness, and $12 \mathrm{~h}$ free access to water and food [all the animals used in this study were cared for in accordance with the principles outlined in the "Guide for the Care and Use of Laboratory Animals" issued by the Animal Care ethical Committee IMS, BHU. Suspension of silver nanoparticles was fed to pregnant mice $(1 \mathrm{ml}$ every day with $0.37,0.65,13$ and $21 \mathrm{mg} / \mathrm{kg}$ between from $2,3,4,5$ treated groups) by oral gavages for 27 days.
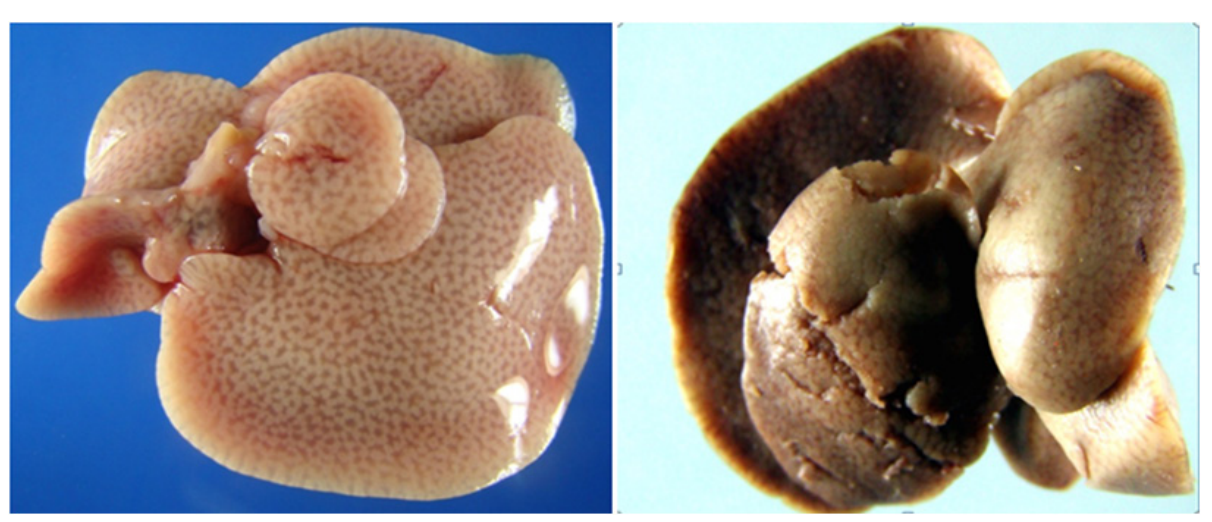

Figure 1:

A. Control pregnant mice liver.

B. Small size AgNps higher dose (13mg/ $\mathrm{kg}$ between) treated liver of pregnant mice showing multiple hemorrhagic focuses and weak with sink appearance. The color appears somewhat blackish grey and brown mixed.

\section{Result}

There were drastic histological changes seen in the pregnant mice vital visceral organs like liver, spleen and kidney which were exposed to small size silver nanoparticles colloidal solution of (13 and $21 \mathrm{mg} / \mathrm{kg}$ dose). In the above dose significant histological $(p>0.005)$ and insignificant morphological changes $(p<0.005)$ seen in spleen, kidney and liver of the experimental mice groups that were treated with small size silver nanoparticles colloid when compared to the control group. But lower dose group were observed almost similar to control group with very negligible and insignificant changes ( $p>0.005$ ) in both histology and morphology. Silver nanoparticles ( 2.45 to 19.53 nanometer size range) caused changes in spleen color from dark brown to reddish black because of internal tissue blood tinged hemorrhage in morphological view and tissue atrophy histologically in pregnant mice in groups 4 and 5 .

But in group 2 and 3 the intensity of histological and morphological appearance was found insignificant when compared to control. This type of result proves that the spleen is one of the target organs for small size silver nanoparticles permeability. The morphological appearance of the kidney and liver in the control group 1 was found normal and healthy, but that of the experimental group 4 and 5 executed drastic changes in color and appearance. The color was found bronze color and the appearance was found weak and sink. In group 2 and 3 same changes was observed in liver and kidney but the intensity was found insignificant when compared to control. The other organs apart from liver, spleen and kidney like vital abdominal and visceral organ did not show significant open eye visual changes. In histological view spleen cell was found in decreasing red pulp state, while white pulp was found in increasing state with adequate lymphocyte penetration and bleeding.

The histological view in treated kidney's tissue demonstrated necrosis of glomerular cells, bowman capsule and proximal tubular region with program cell death sequences in group 4 and 5 in significant intensity while group 2 and 3 exhibited the same features with insignificant intensity. Occult type blood tinged tissue sediments were seen in several regions in histological view in renal tubules PCT and DCT. Program cell death focuses where observed histologically with high intensity in same view. In liver inflammation of lining cells and severe congestion of intra hepatic biliary radicals with multiple and adequate hepatocyte necrosis observed in histological view. Honey comb deformity with vacuolization and intercellular space atrophy with enlargement were observed in the hepatic lobule. Apart from all, apoptosis and necrosis of adequate cells around the central vein and its passing blood cells were also observed in histological view of treated liver tissues.

\section{Discussion}

Small size silver nanoparticles damages multiple and vital abdominal organ tissues like liver, kidney and spleen, the rate 
of damage and disruption found directly proportional to dose of nanosilver in gavages application, i.e., the higher dose (13 and $21 \mathrm{mg} / \mathrm{kg}$ between) of silver nanoparticles showed severe disruption \& damages to the spleen, liver (Figure 2) and kidney tissues of the experimental mice. In this existing study, we tried to evaluate multi abdominal vital organ toxicity as adverse and negative effects of small size silver nanoparticles (2.45 to 19.53 nanometer size range) using pregnant Swiss Albino mice treated with 27 gestational day's regular in morning 9.00 AM oral gavages administration. With addition it, we tried to evaluate the increasing intensity of multi organ toxicity, (Figure 3 ) in the different lower ( $0.37 \& 0.65 \mathrm{mg} / \mathrm{kg}$ between) to higher doses (13 to $21 \mathrm{mg} / \mathrm{kg}$ between) of small size colloidal silver nanoparticles of cooling and magnetic stirring protocol made.

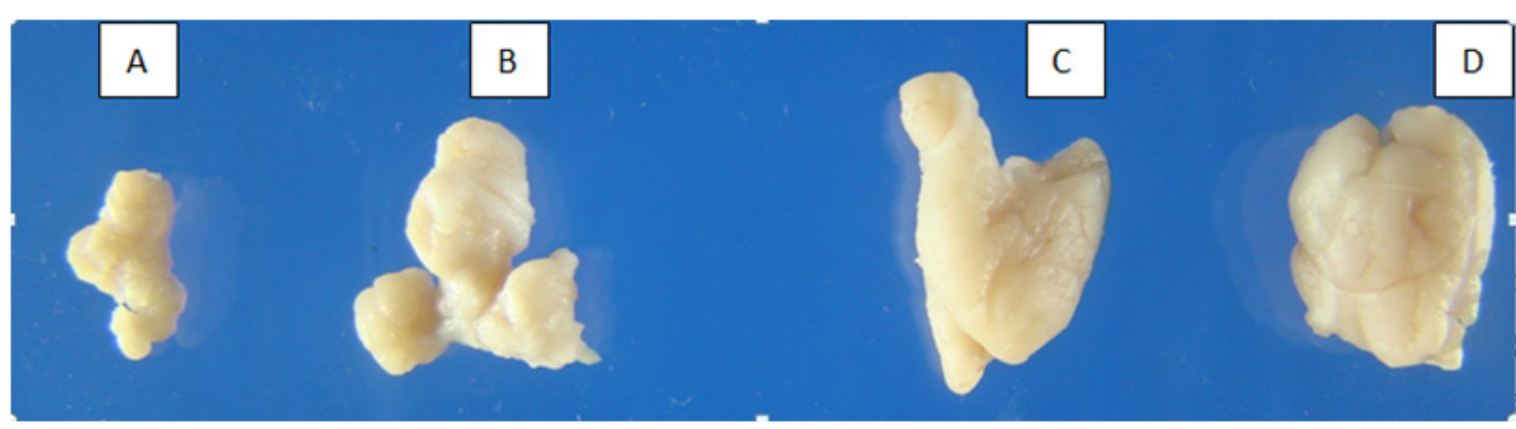

Figure 2:

A. Small size AgNps higher dose (21mg/ kg b.w.) treated pregnant mice pancreas appeared severe weak and sink.

B. Small size AgNps higher dose $(13 \mathrm{mg} / \mathrm{kg}$ b.w.) treated pregnant mice pancreas appeared moderate weak and sink.

C. Control pregnant mice fresh dissected pancreas.

D. Control pregnant mice fresh dissected pancreas.

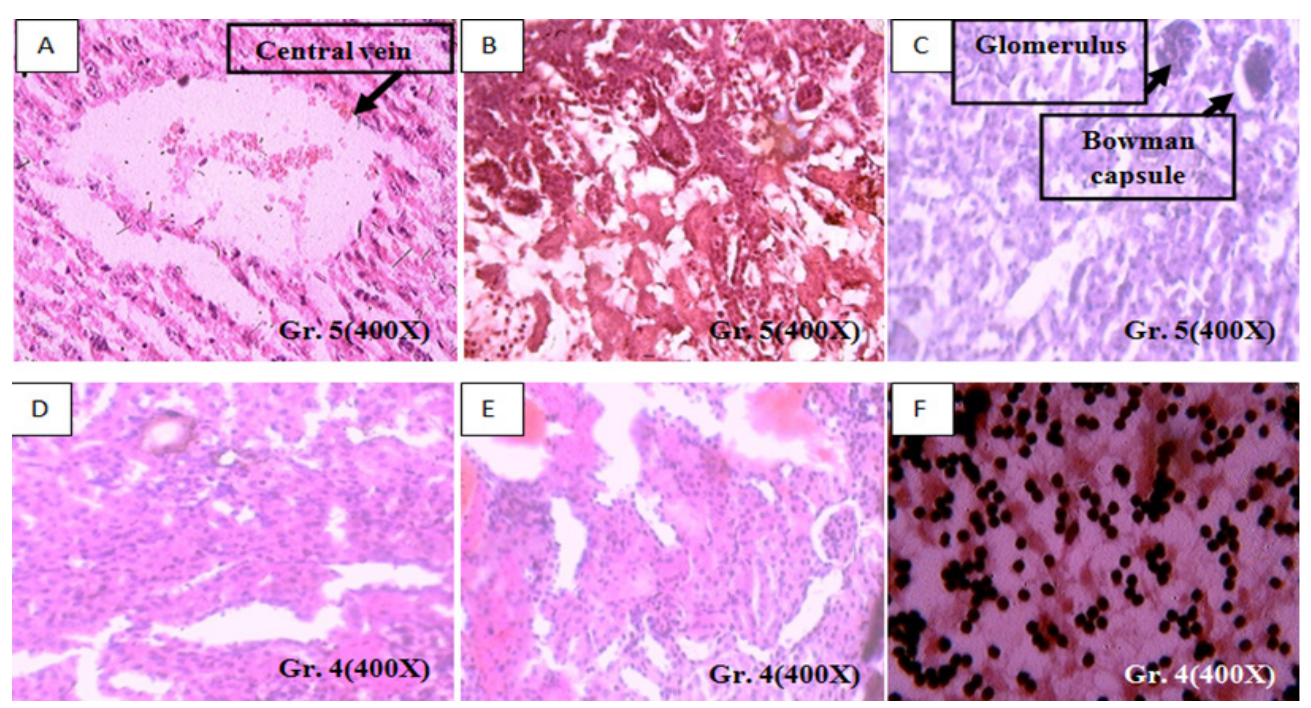

Figure 3:

A. $\quad 21 \mathrm{mg} / \mathrm{kg}$ b.w. small size AgNps treated mother liver histology showing dilatation of central vein with disruption of hepatocyte with IHBR.

B. $\quad 21 \mathrm{mg} / \mathrm{kg}$ b.w. small size AgNps treated pregnant mice kidney histology showing disrupted glomeruli with disruption of DCT.

C. $21 \mathrm{mg} / \mathrm{kg}$ b.w. small size AgNps treated pregnant mice kidney histology showing damaged glomeruli with severe disruption of DCT.

D. $\quad 13 \mathrm{mg} / \mathrm{kg}$ b.w. small size AgNps treated pregnant mice kidney histology showing agenesis glomeruli with severe disruption of DCT \& block with congested PCT.

E. $\quad 13 \mathrm{mg} / \mathrm{kg}$ b.w. small size AgNps treated pregnant mice kidney histology showing damaged glomeruli, multiple hemorrhagic focuses with severe disruption of DCT \& block with congested PCT.

F. $\quad 13 \mathrm{mg} / \mathrm{kg}$ b.w. small size AgNps treated pregnant mice brain histology showing damaged cortical part of cerebrum, multiple, pyknotic nucleus of molecular and granular layer with vacuolization of Lugaro cells of tissues (Honey comb deformity). 


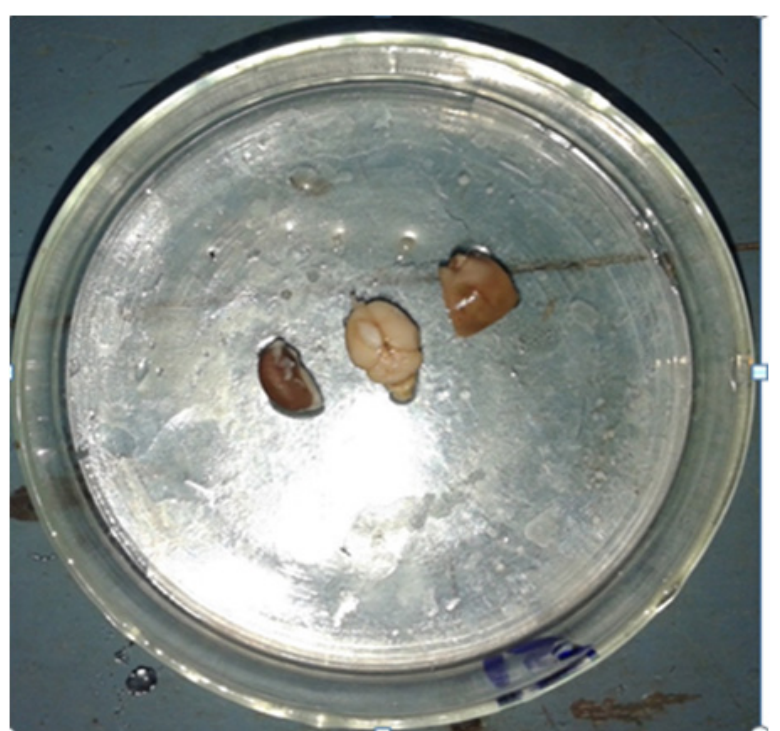

Figure 4: Multi organ toxicity focuses in small size AgNps treated tissues after doing fresh dissection.

Small size silver nanoparticles can enter into the body in different ways but intensity of toxicity rate depends upon mode of permeability and interference $[7,8]$. Some of the past researchers injected bare powdered silver nanoparticles (18 to $32 \mathrm{~nm}$ ) with 1.5 molar $\mathrm{NaCl} 2$ into blood vessels with doses of $0.26 \mathrm{mg} / \mathrm{kg}$, $0.6 \mathrm{mg} / \mathrm{kg}$, and $1.1 \mathrm{mg} / \mathrm{kg}$. After injecting it induced hepatotoxicity (Figure 4) after repeated oral gavages administration. Removal of the macrophages by phagocytosis process in liver yields oxygen radicals of superior group. Cell membrane death is caused by higher radical liberation and led to organ deactivation. In this existing study, we have reported that glomerular necrosis and necrosis of proximal tubular of kidney with congestion of PCT and DCT in high dose (Figures $3 \& 5$ ). Immune system depletion led to multi organ toxicity and disease, but infectious agents and toxins causes' tubule disruption. Apart from this, anatomical structure deviation leads to toxicity and damage of organs [9]. In this present experiment, the tubular damage caused by the toxic effects of small size silver nanoparticles increases glomerular pressure and causes Glomerular atrophy which is nothing but one aspect of multi organ toxicity (Figure 3) (histology), (Figure 6)(gross).

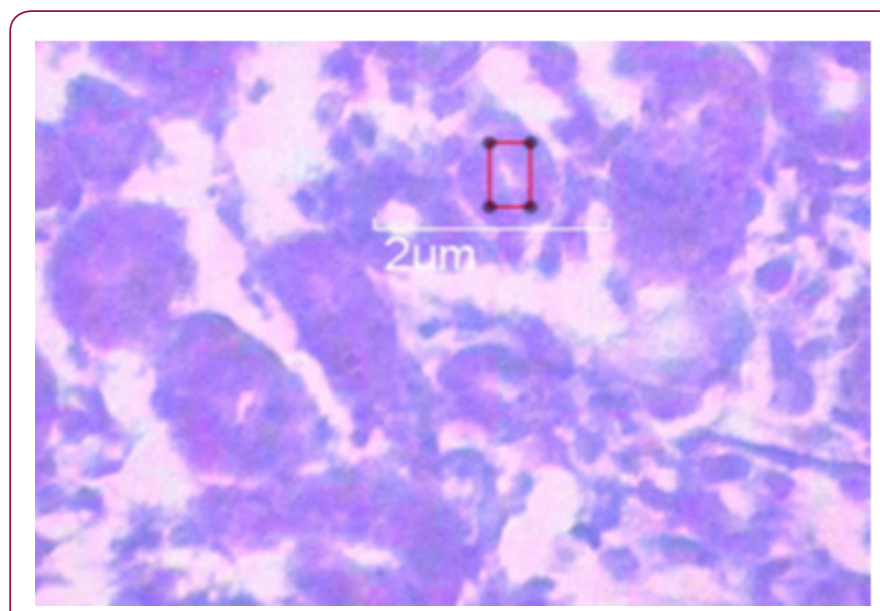

Figure 5: Multi organ toxicity focuses in small size 13 $\mathrm{mg} / \mathrm{kg}$ between AgNps treated kidney cortical fetus tissues showing severe congestion of proximal convoluted tubules.

Scientists of recent era reported that small size silver nanoparticles were highly toxic in lower animals excised and isolated liver cells after successful penetration (Figure 7). It reduces mitochondrial activity which ultimately reduces cell's energy $[10,11]$. Small size AgNps finally deposit and accumulate in the liver, kidney and spleen like vital viscera and cause severe multi organ toxicity also distributes throughout body in form of metal silver and silver salts. Some researchers from past era discovered that, small size AgNps cause the increment of smooth penetration of potassium and sodium through cell membrane, and disrupt the activity of mitochondria [12,13]. Scientists also reported that small size AgNps cause multi organ like liver (Figure 3a) and kidney toxicity (Figure 3) in high dose and in In-vivo and Invitro application leads to death [14]. Scientist also observed spleen toxicity in histological view in the form of disruption of red and white palp (Figure 6).
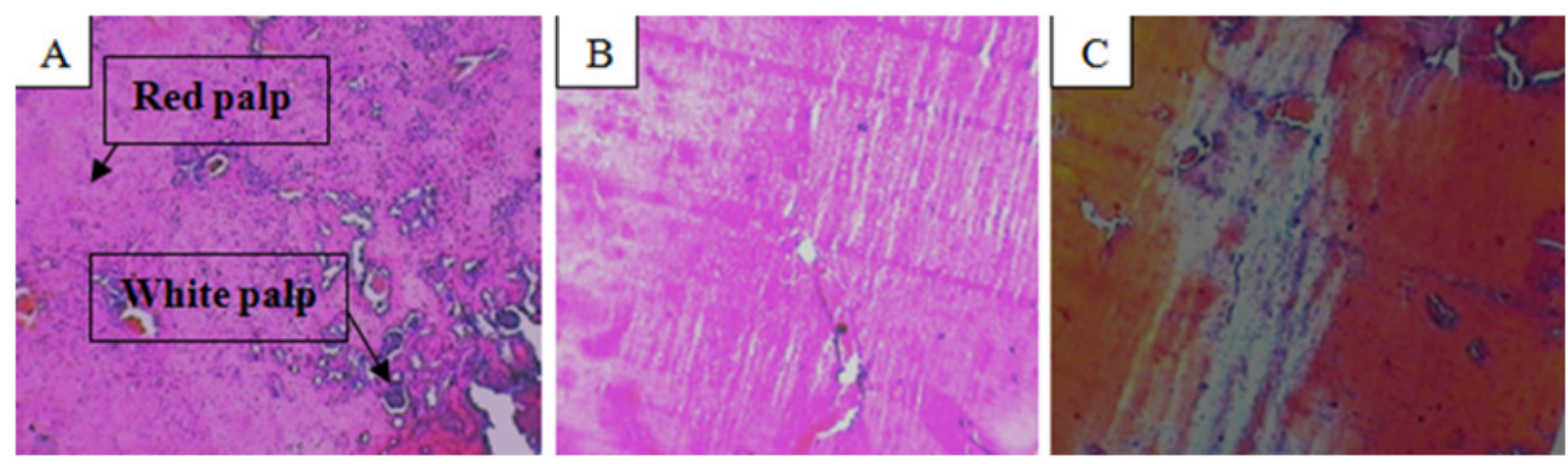

Figure 6:

A. Histological changes seen in $13 \mathrm{mg} / \mathrm{kg}$ b.w. AgNps treated mice spleen showing disrupted red palp and white palp.

B. Histological changes seen in $13 \mathrm{mg} / \mathrm{kg}$ b.w. AgNps treated mice spleen showing disrupted red palp and white palp.

C. Combine Alizarin alcian blue stain. 


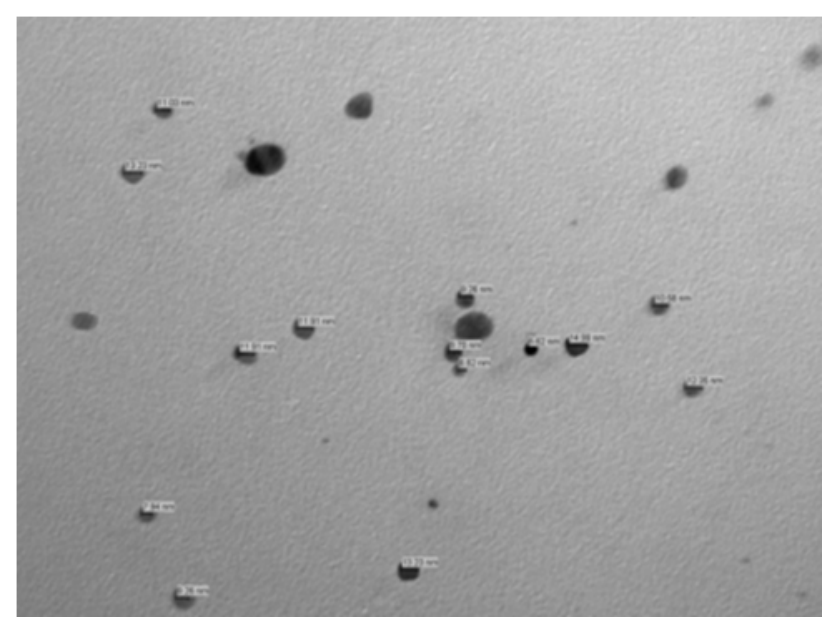

Figure 7: Transmission electron microscopy image of small size AgNps in colloidal stirring and cooling solution form.

Toxicity is nothing but tendency of ionic Ag to bind with a specific chemical in liver which changes normal histology in multi visceral organ, lead to reduction reactions, transferring of GSSG to bile in gall bladder and urine in urinary bladder which reduces the concentration and $\mathrm{Ph} . \mathrm{O} 2$ removal is possible because of this mechanism $[9,15]$. So, different small size AgNps produces multi organ toxicity in human and animal tissues $[16,17]$. We hope with more researches in relation with multi organ toxicity in various small sizes AgNps and various lower and higher doses with various shapes and size effects of small size colloidal nanosilver consumption in in-vivo and in-vitro application mode on body tissues will bounces ahead and become advanced.

\section{Conclusion}

The target of this existing study was to evaluate the potential multi organ toxicity and the general mechanism in small size nanosilver toxicity. The effects of small size nanosilver on multi visceral vital organ like spleen, liver and kidney tissues which were investigated in analytical experiments showed significant damages and toxicity in multi organ tissues in in-vivo \& in-vitro application mode. This multi organ toxicity was evoked by the increase production of free radicals and stimulation of oxidative stress.

\section{Acknowledgement}

This work was supported by the UGC and Department of Anatomy, IMS, BHU.

\section{References}

1. Hillyer JF, Albrecht RM (2001) Gastrointestinal persorption and tissue distribution of differently sized colloidal gold nanoparticles. Pharm Sci 90(12): 1927-1936.

2. Oberdo Rster G (1990) Increased pulmonary toxicity of ultrafine particles Lung lavage studies. J Aerosol Sci 21: 384-387.

3. Bockmann J, Lahl H, Eckert TH, Unterhalt B (2000) Blood Titan Blutspiegel vor und nach Belastungs versuchen mit Titandioxid. Pharmazie 55(2): 140-143.

4. Park EJ, Bae E, Yi J, Kim Y, Choi K, Lee SH (2010) Repeated-dose toxicity and inflammatory responses in mice by oral administration of silver nanoparticles. Environ Toxicol Pharm 30(2): 162-168.

5. Braydich Stolle L, Hussain S, Schlager JJ (2005) In vitro cytotoxicity of nanoparticles in mammalian germline stem cells. Toxicol Sci 88(2): 412419.

6. Chen X, Schluesener HJ (2008) Nanosilver: a nano product in medical application. Toxicol Lett 176(1): 1-12.

7. Edwards Jones V (2009) The benefits of silver in hygiene, personal care and healthcare. Lett Appl Microbiol 49(2): 147-152.

8. Nel A, Xia T, Mädler L, Li N (2006) Toxic potential of materials at the nano level. Science 311(5761): 622-627.

9. Hendi A (2010) Silver nanoparticles mediate diffrential responses in some of liver and kidney functions during skin wound healing. J King Saud Univ Sci.

10. Chen X, Schluesener HJ (2008) Nanosilver: a nano product in medical application. Toxicol Lett 176(1): 1-12.

11. Hussain SM, Hess KL, Gearhart JM, Geiss KT, Schlager JJ (2005) In vitro toxicity of nanoparticles in BRL 3A rat liver cells. Toxicol In Vitro 19(7): 975-983.

12. Oberdo Rster G (1990) Increased pulmonary toxicity of ultrafine particles Lung lavage studies. J. Aerosol Sci 21: 384-387.

13. Lam CW, James JT, McCluskey R, Arepalli S, Hunter RL (2006) A review of carbon nanotube toxicity and assessment of potential occupational and environmental health risk. Crit Rev Toxicol 36(3): 189-217.

14. Tang J, Xi T (2008) Status of biological evaluation on silver nanoparticles. Beijing University of Sci Technol 25(4): 958-961.

15. Campen MJ, McDonald JD, Gigliotti AP, Seilkop SK, Reed MD (2003) Cardiovascular effects of inhaled diesel exhaust in spontaneously hypertensive-rate. Cardiovas Toxicol 3(4): 353-361.

16. Miura N, Shinohara Y (2009) Cytotoxic effect and apoptosis induction by silver nanoparticles in HeLa cells. Biochem Biophys Res Commun 390(3): 733-737.

17. Choi JE, Kim S, Ahn JH, Youn P, Kang JS, et al. (2009) Induction of oxidative stress and apoptosis by silver nanoparticles in the liver of adult zebra fish. Aquat Toxicol 100(2): 151-159. 


\begin{tabular}{|l} 
BIOMEDICAL \\
RESEARCHES
\end{tabular}$\quad \begin{aligned} & \text { Assets of Publishing with us } \\
& \text { - Immediate, unrestricted online access }\end{aligned}$

